\title{
A EDUCAÇÃO DO CORPO NA SOCIEDADE DO CAPITAL
}

\author{
BODY EDUCATION IN THE SOCIETY OF CAPITAL
}

\section{LA EDUCACIÓN DEL CUERPO EM LA SOCIEDAD DEL CAPITAL \\ Rogério Cruz de Oliveira ${ }^{1}$ \\ ${ }^{1}$ Universidade Federal de São Paulo (UNIFESP), Santos/SP-Brasil}

Resumo Trata-se de uma resenha do livro "A Educação do corpo na sociedade do capital", o qual tematiza os limites do corpo na sociedade capitalista e seus desdobramentos para a educação. A obra inspira reflexões para educadores em relação às demandas sociais para um corpo belo e saudável.

RESumen Se trata de uma revisión del libro "A Educação do corpo na sociedade do capital", que se ocupa de los limites del cuerpo en la sociedad capitalista y sus ramificaciones para la educación. El libro inspira reflexiones para educadores en relación a las demandas sociales para un cuerpo bello y sano.

ABSTRaCt It is a book review of "A Educação do corpo na sociedade do capital”, which adresses the limits of body in a capitalist society, and their impacts to education. The work inspires some reflexions to educators faces to social demands from beauty and healthy body.

Livro: BAPTISTA, Tadeu João Ribeiro. A Educação do corpo na sociedade do capital. Curitiba: Appris, 2013, 246p.

O livro de Tadeu João Ribeiro Baptista é o primeiro do professor da Faculdade de Educação Física e Dança da Universidade Federal de Goiás. O professor é membro pesquisador do Laboratório de Pesquisa em Ciências Humanas e Naturais Aplicadas à Educação Física e do Laboratório de Pesquisa sobre Corpo, Sociedade e Natureza, ambos da mesma instituição.

O livro é prefaciado por Beleni Saléte Grando, que compreende a relevância da obra pela profundidade que o autor trabalha a questão da direção que a educação do corpo se 
estabelece nessa sociedade, bem como, o diálogo feito com os grandes clássicos das ciências sociais.

Em sua introdução, o autor sintetiza a história do corpo evidenciando as diferentes matrizes teórico-metodológicas empenhadas no estudo da temática. Entretanto, dá destaque ao papel da indústria cultural em sua interface com a saúde, com a estética e com o lazer.

No primeiro capítulo - "O trabalho e a construção do homem" - Baptista afirma que o trabalho é uma atividade dos seres humanos e responsável por sua diferenciação frente aos outros animais, bem como, consiste na relação do homem com a natureza e é determinada pelo capital. Nessa esteira, discorre sobre a constituição do corpo humano pelo trabalho, afirmando que os produtos desenvolvidos pelos seres humanos por meio de seu trabalho se manifestam por intermédio do seu corpo e possuem conexões naturais e sociais, configurando a totalidade. Nessa ótica, reafirma que a produção e a transformação da natureza são fundamentais para a transformação dos próprios seres humanos e que o trabalho se responsabiliza pela educação dos seres humanos, por conseguinte, educando o corpo.

Já no capítulo dois - "O trabalho no capitalismo e a educação do corpo" - o autor se propõe a discutir sobre a alienação, o fetiche e a reificação como marcas do capitalismo e seus desdobramentos para a educação do corpo. No que se refere à alienação, Baptista assevera que o trabalho repetitivo e contínuo desenvolvido no modo de produção capitalista produz alienação, já que: o trabalhador não se reconhece no produto produzido; o trabalhador torna-se apenas um mero meio de produção, espécie de máquina, e; o homem se perde de si, uma vez que não se reconhece mais como ser humano, por consequência perdendo sua capacidade de se relacionar com a natureza. Em relação ao fetiche, o autor discute a respeito da mercadoria, afirmando que toda ela tem seu valor e que este possui relação com a quantidade de trabalho humano gasto para a confecção do produto, porém também construído pelo processo produtivo. Ou seja, arremata o autor: o valor é puramente social. Diante do exposto, chega-se ao fetichismo, que, para Baptista, se traduz no controle que a mercadoria passa a exercer na sua relação com os homens. Nesse ínterim, assegura que o trabalho transforma, pelo fetichismo da mercadoria, as capacidades do trabalhador ao seu regime, porém, como o trabalhador também é mercadoria se torna, portanto, uma coisa, dando vazão ao processo de reificação do homem. Para Baptista, a reificação se relaciona com a racionalização e a mecanização próprias do sistema capitalista, o qual, ao fragmentar o objeto, fragmenta também o sujeito que o produz. Dessa forma, o ser humano faz parte do mercado e vende suas capacidades. Em suma, quando o trabalho determina a alienação, a fetichização e a reificação, também define a condição de existência do ser humano em suas várias esferas, principalmente a corporal. Baptista assevera que o corpo é construído histórica e socialmente e sempre foi meio de trabalho, porém, é no modo de produção capitalista que a relação entre corpo e trabalho ganha fortes laços, sendo o corpo a mercadoria vendida pelo trabalhador ao patrão. Nesse contexto, o capital consome força de trabalho e o corpo orgânico do homem, exigindo que o trabalhador se mantenha em condições de força, saúde e disposição para suportar a jornada. Além disso, reforça o autor, o tipo de trabalho determina ainda um padrão de corpo para garantir as condições necessárias de produção, 
o que, por conseguinte, o levará a possuir uma referência. Segundo Baptista, valoriza-se assim a capacidade de trabalho do corpo, podendo ser medida pela força, resistência, agilidade e magreza, sendo esse modelo de corpo desejado em todos os espaços. Nesse aspecto, ganham terreno as ciências naturais, que, para o autor, ao quantificar processos e recomendar adequações, acabam imputando um padrão corporal a todos, corroborando a produção/ reprodução do sistema. Assim, a obra afirma que está em curso o desenvolvimento de uma racionalidade tecnológica e instrumental que imprime ao corpo uma série de necessidades de forma e capacidades, fazendo que a reificação se torne o processo educativo e se dissemine nas diversas instituições sociais, por exemplo, a escola.

No capítulo 3 - "O corpo na tensão entre a produção e o consumo" - o livro traz à tona a discussão sobre a indústria cultural como um dos pilares da sociedade capitalista, que se atarefa em disseminar suas ideias vinculadas à produção e reprodução. Em termos conceituais, Baptista afirma ser a indústria cultural uma pressão que a sociedade faz sobre o indivíduo por meio da utilização de elementos culturais acessíveis pela televisão, cinema, rádio, internet e outras formas de comunicação de massa, de modo a cooptar as pessoas aos interesses do mercado. Para tanto, assevera o autor, a mercadoria produzida necessita ser dotada de certa padronização, sendo privilegiada a racionalidade técnica, a massificação e, ainda, a invasão do tempo livre do trabalhador pela lógica do trabalho, garantindo assim a produção e a reprodução do sistema. Para tanto, as mercadorias, embora pareçam diferenciadas, são produzidas e circuladas para serem consumidas em larga escala sem estímulo para reflexão, sendo pré-digeridas e/ou padronizadas, inclusive o corpo. Nessa perspectiva, o consumo de roupas, acessórios, dietas, tratamentos estéticos, cirurgias etc. pode ser considerado uma manifestação da indústria cultural na vida em sociedade, que, sob a égide do discurso da saúde, bem-estar e qualidade de vida, se esconde a necessidade capitalista de controlar o corpo e mantê-lo em condições de prontidão para o trabalho. $\mathrm{Na}$ mesma linha, o autor argumenta que o treinamento corporal é privilegiado como forma de evitar a degeneração orgânica, bem como, garantir o lucro do patrão, caso contrário o modo de produção perde as condições necessárias à sua reprodução. Além disso, o livro argumenta que a mensuração do corpo é adotada como estratégia para identificar/fiscalizar se ele se encontra adequado, bem como, classificá-lo segundo padrões de normalidade, indo ao encontro da magreza, da beleza e da juventude. Para o autor, a consolidação desse processo de educação do corpo se dá pelos meios de comunicação, pois estes alastram essas informações com o mesmo tipo de argumentação e, que, facilmente são reproduzidos pelas pessoas em seus diversos espaços de convívio social. $\mathrm{O}$ autor finaliza o capítulo afirmando que só é possível a superação desse modelo por meio de intervenção crítica em outro modelo social, que favoreça o desenvolvimento da autonomia e emancipação das pessoas com outro projeto educativo.

Em sua conclusão, Baptista afirma que a educação é um processo de constituição humana do ser na sua relação com a realidade e que possui a tarefa de consolidar uma consciência compromissada com a emancipação, interferindo, inclusive, no corpo. Com isso, é favorável a uma educação para a resistência, comprometida com outro mundo para as pessoas. 
Frente ao exposto, a leitura do livro de Tadeu João Ribeiro Baptista se destina ao público acadêmico das ciências humanas em geral e, em específico, àqueles que estão no terreno da educação escolar. Isso porque, na atualidade, é a escola a instituição na qual todas as crianças e adolescentes passarão uma parte de suas vidas e desenvolverão relações com seus pares e/ou professores. Mesmo compreendendo, conforme Brandão (1995), que a educação está presente em todos os lugares, é na escola que ela ganha contornos únicos e, para usar uma expressão de Baptista, de produção/reprodução social. Numa análise mais ampla e talvez simplista, o texto de Baptista estaria destinado aos professores de Educação Física, que, pressionados aos apelos de saúde, bem-estar e qualidade de vida da sociedade estariam propensos a usar o tempo das aulas de Educação Física na escola para promover labor corporal aos alunos com vistas às rigorosas adequações sociais, ávidas pelo corpo esguio, belo e dócil.

Entretanto, o livro inspira reflexões para todos os atores educacionais, pois embora o corpo seja temática privilegiada da Educação Física, e a temática não pode passar despercebida nem ser exclusiva de um só componente curricular, principalmente porque a escola se tornou, ao longo de sua existência, um espaço rígido de controle do corpo. Além disso, os clássicos estudos educacionais são recorrentes em afirmar que a escola é uma instituição que privilegia a manutenção da ordem, da hierarquia e de ritos que contradizem teorias de aprendizagem. Segundo Ayoub (2005), várias são as situações nas quais os alunos nas escolas são tratados como cabeças pensantes pela escola.

Nesse sentido, embora a temática já possua debate acumulado na Educação Física desde a década de 1980 em distintas correntes teóricas, tendo destaque à época a obra de João Paulo Subirá Medina "A Educação Física cuida do corpo... e mente" (1983 - já está em sua $24^{\mathrm{a}}$ edição), e nos dias de hoje nas produções de pesquisadores como Alexandre Vaz (UFSC), Paulo Fensterseifer (UNIJUI), Valter Bracht (UFES), Denize Sant'anna (PUC-SP), o livro do Prof. Tadeu Baptista se mostra inovador na linguagem adotada com o leitor, seguida de exemplificações atuais, bem como, na relação do discurso com as esferas da educação escolar, das academias, do lazer etc.

Em suma, trata-se de uma leitura para os educadores que desejam ampliar - "incorporar" - a compreensão sobre os desdobramentos do capitalismo na vida social.

\section{ReferênCIAS}

AYOUB, Eliana. Memórias da educação física escolar. In: CONGRESSO BRASILEIRO DE CIÊNCIAS DO ESPORTE, 14, 2005, Porto Alegre. Anais.... Porto Alegre: ESEF/ UFRGS, 2005, p. 2.260-2.270.

BRANDÃO, Carlos Rodrigues. O que é educação, 33. ed. São Paulo: Brasiliense, 1995. MEDINA, João Paulo Subirá. A Educação Física cuida do corpo ... e mente. Campinas: Papirus, 1983. 
Dados do Autor

\section{Rogério Cruz de Oliveira}

Doutor em Educação Física. Professor da Universidade Federal de São Paulo - Campus Baixada Santista. Santos/SP. rogerio.cruz@unifesp.br

Submetida em: 21-9-2018

Aceita em: 1-2-2019 